\title{
Thematic processing of adjuncts: Evidence from an eye-tracking experiment
}

\author{
SIMON P. LIVERSEDGE \\ University of Durham, Durham, England \\ MARTIN J. PICKERING \\ University of Edinburgh, Edinburgh, Scotland \\ EMMA L. CLAYES \\ University of Glasgow, Glasgow, Scotland \\ and \\ HOLLY P. BRANIGAN \\ University of Edinburgh, Edinburgh, Scotland
}

\begin{abstract}
We investigated thematic processing in sentences containing a prepositional phrase that was ambiguous between a locative and a temporal interpretation. We manipulated context (temporal or locative), target sentence (temporal or locative), and whether or not the main verb of the target and the context was repeated. Results showed that context dictated the participants' thematic expectations. Thematically, congruent target and context pairs were read faster than incongruent pairs. This effect was not modulated by verb repetition. We argue that $w h$-words cause readers to lodge semantically vacuous thematic roles in their discourse representation that bias a reader's interpretation of subsequent thematically ambiguous adjuncts in their discourse representation.
\end{abstract}

Thematic roles, such as agent, patient, and location, have played an important part in linguistic theory for almost 40 years (e.g., Dowty, 1991; Fillmore, 1968; Gruber, 1965). It is not surprising, therefore, that psycholinguists have investigated how they are encoded and how they affect comprehension (e.g., Abney, 1989; Carlson \& Tanenhaus, 1988; Clifton, Speer, \& Abney, 1991; Ferretti, McCrae, \& Hatherall, 2001; Liversedge, Pickering, Branigan, \& Van Gompel, 1998; Rayner, Carlson, \& Frazier, 1983; Schütze \& Gibson, 1999). In this paper, we report an eye-tracking investigation of thematic role assignment during the comprehension of sentences containing ambiguous adjuncts.

Most work on sentence processing has focused on the way in which people obtain an interpretation for an individual word or how they assign an appropriate syntactic analysis for an utterance as a whole. A rather separate body of work is concerned with the more global processes of text comprehension. The assignment of thematic roles to phrases is a process that is relevant to both of these stages

The research described in this paper was supported by Economic and Social Research Council Grant R000 222647 awarded to S.P.L. We are grateful to three anonymous reviewers, Keith Rayner, Roger van Gompel, and Sarah White for helpful comments about this work. Correspondence concerning this article should be addressed to S. P. Liversedge, Department of Psychology, University of Durham, Science Laboratories, South Road, Durham DH1 3LE, England (e-mail: s.p.liversedge@ durham.ac.uk). and may provide something of a link between them. Thematic role assignment during sentence processing involves making decisions about the event described by a verb and its relation to entities, locations, and times specified in the sentence. In nontechnicalterms, thematic role assignment involves establishing who or what did what to whom and when or where that event took place.

When people identify a verb, they obviously must determine its meaning and syntactic category. In addition, they must establish what arguments it may or must take (its subcategorization frame) and what general types of meanings these arguments must have (its thematic grid). The subcategorization frame associated with the lexical entry for the verb kiss specifies that this verb takes two noun phrase arguments. The thematic grid associated with kiss specifies that these two arguments take the roles of agent (entity performing the action of the verb) and patient (entity receiving the treatment of the verb). In Sentence 1 below, these roles are assigned to Mary and John, respectively:

\section{Mary kissed John in the kitchen.}

However, only thematic roles associated with arguments are licensed by the verb's thematic grid. In addition to arguments, sentences may also include adjuncts to which thematic roles are also assigned (e.g., in the kitchen in Sentence 1. Roles associated with adjuncts are licensed by elements other than the verb. In Sentence 1, in the kitchen is an adjunct phrase that is assigned a location 
role that is licensed by the preposition in. Assignment of thematic roles to the different constituents of a sentence permits the computation of the fundamental meaning of that sentence. Carlson and Tanenhaus (1988) proposed that people access the thematic grid of a verb and assign thematic roles to arguments immediately after they encounter the verb. On this account, as soon as people process kissed in Sentence 1, they assign Mary the agent role associated with kissed, and as soon as they encounter John, they assign it the patient role. Although Carlson and Tanenhaus make no specific claim about how thematic roles are assigned to adjuncts, the natural assumption is that they are also assigned as soon as possible.

Some evidence suggests that assignment of thematic roles to adjuncts is costly in comparison with assignment of thematic roles to arguments. Liversedge et al. (1998) monitored eye movements while participants read sentences containing phrases that were ambiguous between an argument and an adjunct interpretation. They presented agentive target sentences (e.g., Sentence 4) and locative target sentences (e.g., Sentence 5) in isolation or preceded by a context that supported either an agentive argument interpretation (e.g., Sentence 2) or a locative adjunct interpretation (e.g., Sentence 3):

2. The head gardener wondered about who should plant the shrubs.

3. The head gardener wondered about where to plant the shrubs.

4. In fact, the shrubs were planted by the apprentice that morning.

5. In fact, the shrubs were planted by the greenhouse that morning.

In isolation, gaze durations for the disambiguating words (apprentice, greenhouse) were shorter for the agentive than for the locative sentences. Liversedge et al. (1998) argued that readers prefer to process ambiguous phrases initially as arguments rather than as adjuncts. In accord with the predictions of Abney (1989), Schütze and Gibson (1999) found a preference for argument over adjunct (modifier) interpretations, using prepositional phrase modifiers in sentences containing syntactic ambiguities. In fact, their results showed that this preference was sufficiently strong that it outweighed any preference for adopting the minimal attachment analysis (Clifton et al., 1991; Frazier, 1987; Rayner et al., 1983). Finally, Ferretti et al. (2001) found that verbs immediately prime typical agents and patients (as well as instruments), but not locations. This suggests that argument information is accessed more rapidly than adjunct information.

More specifically, Boland and Boehm-Jernigan (1998) have claimed that arguments and adjuncts are attached via different mechanisms. Arguments are lexically specified, and thematic roles that are assigned to them semantically constrain the argument's participatory role in the event. By contrast, adjunct attachments are specified by global syntactic rules and, therefore, are not lexically specified. Arguments are lexically specified and compete on the basis of frequency; whereas adjuncts are spec- ified by global syntactic rules and do not compete. Boland and Boehm-Jernigan argued that lexically specified attachments take precedence over attachments licensed by global syntactic rules and, hence, that there is a processing cost for adjuncts, relative to arguments. This finding is in accord with Liversedge et al.'s (1998) first experiment. However, not all theories recognize a qualitative distinction between the processing of arguments and adjuncts. For example, MacDonald, Pearlmutter, and Seidenberg (1994) claimed, in contrast to Boland and Boehm-Jernigan, that both arguments and adjuncts are lexically specified and compete on the basis of frequency; any difference between the processing of arguments and adjuncts arises from differences in their relative frequencies.

Liversedge et al. (1998) also found that gaze durations for the disambiguating word of locative target sentences preceded by locative contexts, such as Sentence 3, and agentive target sentences preceded by either agentive contexts, such as Sentence 2, or locative contexts did not differ. However, gaze durations for the disambiguating word of locative target sentences preceded by agentive contexts were longer. Thus, preceding context removed any difficulty associated with adjunct sentences but did not induce any difficulty for argument sentences. They argued that the $w h$-word in the context caused the reader to lodge a semantically vacuous thematic role in their discourse representation. Consequently, empty thematic roles can become available both from the thematic grid of the verb in the target sentence and from the discourse representation. An agent thematic role was always available from the verb's thematic grid regardless of context, so agentive $b y$-phrases never produced difficulty. In contrast, a locative role was not available from the verb's thematic grid, so a locative $b y$-phrase was straightforward only when the locative context introduced this role.

In Liversedge et al. (1998), one version of the target sentence contained an argument, and the other contained an adjunct. However, their account makes interesting predictions about thematic ambiguities when both alternatives are adjuncts, such as Sentences 6 and 7:

6 . The maid peeled the vegetables in the morning, with great care.

7. The maid peeled the vegetables in the kitchen, with great care.

In Sentence 6, the prepositional phrase is assigned a temporal thematic role, whereas in Sentence 7, it is assigned a location thematic role. According to Liversedge et al. (1998), there should be no default preference for a temporal or a locative interpretation, since neither is an argument of the verb. However, if such sentences were preceded by a context containing either a locative $w h$-word (e.g., Sentence 8) or a temporal wh-word (e.g., Sentence 9), these should bias the reader to assign either a locative thematic role or a temporal thematic role to the ambiguous prepositional phrase:

8. The maid wondered where to peel the vegetables.

9. The maid wondered when to peel the vegetables. 
After a locative context, the wh-word where should cause readers to lodge an empty locative role in their discourse representation, whereas after a temporal context, the wh-word when should cause the reader to lodge an empty temporal role in their discourse representation. Consequently, the nature of the context should dictate the thematic role readers initially assign to the ambiguous prepositional phrase. Reading times should be longer when context and target sentences are thematically incongruent than when they are congruent.

Hence, the finding of incongruency effects would provide support for Liversedge et al.'s (1998) account. However, we might expect some differences in the effects for prepositional phrases that are ambiguous between two adjunct interpretations, as compared with prepositional phrases that are ambiguous between an adjunct and an argument interpretation. The order of adjuncts is much freer than the order of arguments. In particular, a locative adjunct may felicitously precede a temporal adjunct (e.g., the maid peeled the vegetables in the kitchen in the morning), or vice versa (e.g., the maid peeled the vegetables in the morning in the kitchen). In contrast, arguments generally precede adjuncts, so that the shrubs were planted by the greenhouse by the apprentice is much less felicitous than the shrubs were planted by the apprentice by the greenhouse. Consequently, the context sentence the maid wondered where to peel the vegetables could be followed by the maid peeled the vegetables in the morning in the kitchen without any clear infelicity. Thus, for sentences containing prepositional phrases that are ambiguous between two adjunct interpretations, it is quite possible that it becomes clear that there is a thematic incongruity between the context and the target sentences only toward the end of the target sentence and, so, thematic congruity effects might be delayed. In contrast, since arguments generally precede adjuncts, the shrubs were planted by the greenhouse by the apprentice is much less felicitous than the shrubs were planted by the apprentice by the greenhouse. Thus, for prepositional phrases that are ambiguous between arguments and adjuncts, it is clear early in the target sentencespecifically, at the disambiguating noun phrase-whether the context and the target sentences are incongruent.

A second aspect of the thematic assignment process that we tested in this experiment is how empty thematic roles introduced by an interrogative $w h$-word in a context sentence are stored in the discourse representation. It is possible that empty thematic roles introduced by $w h$ words are associated with specific lexical items in the discourse representation. For example, in Sentence 9, the semantically vacuous temporal thematic role introduced by the $w h$-word when might be associated only with the specific lexical entry for the verb peel. If so, the reader should assign a temporal role only to subsequent adjuncts associated with this lexical item.

Alternatively, Ferretti et al. (2001) argued that thematic roles are tightly associated with schematic knowledge and that verbs might provide immediate access to a generalized knowledge structure (possibly a situation schema) that contains information about the situation a verb describes (see also McRae, Ferretti, \& Amyote, 1997). On this account, empty thematic roles introduced by $w h$-words are lodged in this general discourse representation, associated with the meaning of an event rather than with a specific lexical item. Note that both these possibilities are consistent with lexically based theories of language processing (e.g., MacDonald et al., 1994; McRae, Spivey-Knowlton, \& Tanenhaus, 1998), with the former stipulating that limited thematic information is associated with a verb's lexical entry, but the latter advocating that a verb's lexical entry provides access to a more generalized knowledge structure. The aim of the present experiment was to discriminate between these two possibilities. For half of our participants, we repeated the main verb in the context and the target sentence, whereas for the other half, the verb differed between context and target but clearly instantiated the same scenario. We anticipated that if readers associate semantically vacuous thematic roles with specific lexical items, context-target sentence congruency effects should occur only when the verb is repeated. But if readers instantiate discourse representations on the basis of schematic knowledge, context-target congruency effects should occur regardless of whether the verb is repeated.

\section{METHOD}

\section{Participants}

Sixty-four undergraduate students from the University of Durham were paid to participate. They were all native speakers of British English and had normal or corrected-to-normal vision.

\section{Items and Design}

Twenty-eight items were constructed, each consisting of a context and a target sentence pair (see the Appendix). There were eight versions of each item (see Table 1). The items consisted of a context sentence containing the wh-word where (locative context) or when (temporal context), which were designed to introduce either a locative or a temporal thematic role into the reader's discourse representation. The target sentences specified where (locative target sentence) or when (temporal target sentence) a particular event occurred. The target sentences comprised an initial connective, such as in fact, that was never a temporal or a locative phrase, followed by a pronoun referring to the entity performing the action in the context sentence and then either a repetition of the verb from the context sentence or a new verb that was chosen so that the event described was consistent with the context event. For the new verbs, 26 synonyms or near-synonyms and 2 hyponyms were used. The sentence ended with a prepositional phrase comprising in and a noun phrase specifying either the location or the time at which the event took place and a filler phrase. The noun in the prepositional phrase was matched for length and frequency, using the CELEX database (Baayen, Piepenbrock, \& Gulikers, 1995; mean locative frequency $=870$ per million; mean temporal frequency $=853$ per million; $F<1$ ). Target sentences were also matched for plausibility on a 9-point scale (mean locative plausibility $=7.38$; mean temporal plausibility $=7.35 ; F \mathrm{~s}<1)$. We constructed eight lists of items, four containing the versions with the same verb and four containing items with different verbs in the context and the target sentences. Eight participants were randomly assigned to each list. Four lists contained 7 items from each of the same-verb conditions; the other 
Table 1

Example Context and Target Stimuli

\begin{tabular}{|c|c|c|}
\hline Context & Target Sentence & Sentence Pair \\
\hline & & Same Verb \\
\hline \multirow[t]{2}{*}{ Locative } & locative & $\begin{array}{l}\text { The maid thought about where to peel the vegetables. } \\
\text { In fact, she peeled them in the kitchen, with great care. }\end{array}$ \\
\hline & temporal & $\begin{array}{l}\text { The maid thought about where to peel the vegetables. } \\
\text { In fact, she peeled them in the morning, with great care. }\end{array}$ \\
\hline \multirow[t]{3}{*}{ Temporal } & locative & The maid thought about when to peel the vegetables. \\
\hline & temporal & $\begin{array}{l}\text { The maid thought about when to peel the vegetables. } \\
\text { In fact, she peeled them in the morning, with great care. }\end{array}$ \\
\hline & & Different Verb \\
\hline \multirow[t]{2}{*}{ Locative } & locative & $\begin{array}{l}\text { The maid thought about where to prepare the vegetables. } \\
\text { In fact, she peeled them in the kitchen, with great care. }\end{array}$ \\
\hline & temporal & $\begin{array}{l}\text { The maid thought about where to prepare the vegetables. } \\
\text { In fact, she peeled them in the morning, with great care. }\end{array}$ \\
\hline \multirow[t]{2}{*}{ Temporal } & locative & $\begin{array}{l}\text { The maid thought about when to prepare the vegetables. } \\
\text { In fact, she peeled them in the kitchen, with great care. }\end{array}$ \\
\hline & temporal & $\begin{array}{l}\text { The maid thought about when to prepare the vegetables. } \\
\text { In fact, she peeled them in the morning, with great care. }\end{array}$ \\
\hline
\end{tabular}

four lists contained 7 items from each of the different-verb conditions. Each list contained exactly one version of every item. We combined the 28 items with 57 filler sentence pairs of various types to give eight lists of 85 sentence pairs. Forty-two of these pairs were followed by a yes/no question. Thus, we adopted a 2 (verb, same vs. different) $\times 2$ (context, locative vs. temporal) $\times 2$ (target, locative vs. temporal) design. The context and target variables were within subjects and items; the verb variable was between subjects and within items.

\section{Procedure}

The participants' eye movements were recorded with a Fourward Technologies Dual Purkinje Generation 5.5 eye tracker that monitored the right eye (although viewing was binocular). The tracker had an angular resolution of $10^{\prime}$ arc. A computer displayed the items on a screen $80 \mathrm{~cm}$ from the the participants' eyes. The tracker monitored participants' gaze location every millisecond, and the software sampled the tracker's output to establish the sequence of eye fixations and their start and finish times.

Each participant was run individually. Before the experiment began, each participant read instructions explaining the eye-tracking procedure. Each context and target sentence pair appeared on the screen together. The participants were required to read the sentences normally and to try to understand them to the best of their ability. A bite bar and head restraints were used to minimize head movements. Next, the participant completed a calibration procedure. The software calculated the position of eye fixation on the basis of the calibration. After a successful calibration, the texts were presented in two blocks. Calibration was checked before each trial, and the participants were recalibrated whenever necessary. The participants were given a break halfway through the experiment. The items were presented in a fixed random order, with three fillers preceding the first experimental sentence. The experiment took about $30 \mathrm{~min}$.

\section{Analyses}

We first removed trials with major tracker losses and trials in which the readers failed to make a first-pass fixation on the context sentence or two successive regions of the target sentence. In this way, $10 \%$ of the trials were excluded. If a fixation was shorter than $80 \mathrm{msec}$ and within one character space of the previous or next fixation, it was assimilated to this fixation. All remaining fixations shorter than $60 \mathrm{msec}$ were excluded. Following Rayner and Pollatsek
(1989), we assume that readers do not extract much information during such short fixations. Fixations longer than 1,200 msec were also excluded.

The experimental items were divided into seven analysis regions, indicated by slashes in Sentence 10:

10. The maid thought about where to peel the vegetables./ In fact,/ she peeled them/ in the/ kitchen, / with great/ care.

These regions corresponded to (1) the context sentence, (2) the connective, (3) the subject pronoun, verb, and object pronoun, (4) the preposition in and determiner the, (5) the disambiguating temporal or locative noun, (6) the spillover region, and (7) the final region.

We report four eye-tracking measures. First-pass reading time is the sum of all fixation durations in a region until the reader's first fixation outside that region (either to the left or to the right). For regions consisting of a single word, first-pass time corresponds to gaze duration (Rayner \& Duffy, 1986). Rereading time (cf. Liversedge, Paterson, \& Clayes, 2002) is the sum of all fixation durations from the reader's first fixation after regressing from a region until the first fixation to the right of the region. For the final region, we summed all the fixations after a regression until the reader pressed the button to indicate that they had understood the sentence. This constitutes a measure of time spent rereading after the first sweep of the eyes through each region of the text. Total time is the sum of all fixations in a region. For the disambiguating region, we also report first fixation duration, which is the time spent first fixating the disambiguating noun. Prior to conducting the analyses, we removed trials in which two adjacent regions had a zero first-pass time.

\section{RESULTS}

Data for each region were subjected to two verb $\times$ context $\times$ target analyses of variance, one treating subjects as a random variable $\left(F_{1}\right)$ and the other treating items as a random variable $\left(F_{2}\right)$. Mean reading times are reported in Table 2.

First-pass times for Region 2 (the connective) showed no main effect of verb, context sentence, or target sentence and no reliable interactions between any of the variables (all $p$ s > .07). In Region 3, there was an effect 


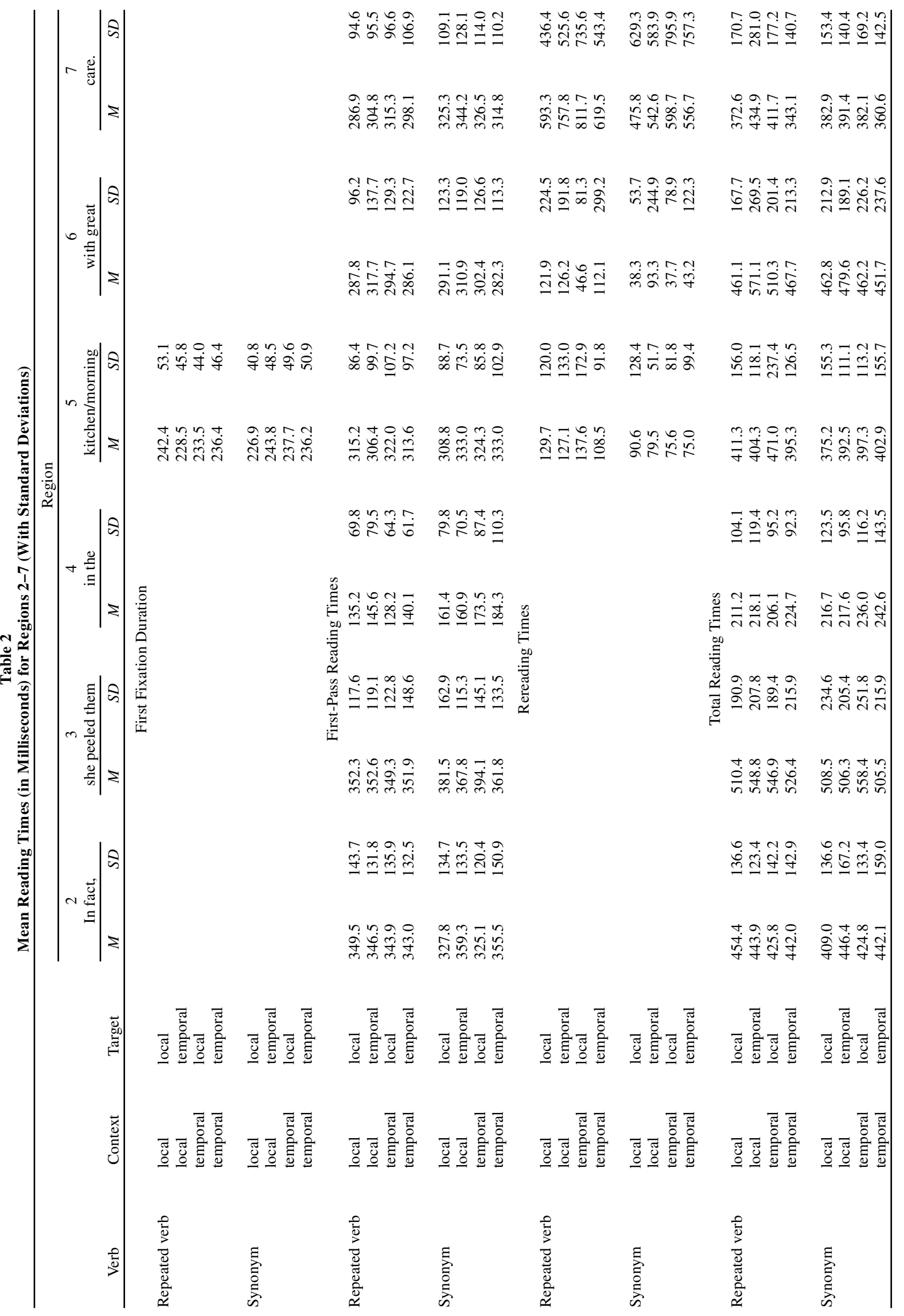


of verb on the items analysis alone $\left[F_{1}<1 ; F_{2}(1,27)=\right.$ $8.85, p<.01]$. No other effects approached significance (all $p \mathrm{~s}>.18$ ). In Region 4 (in the), the effect of verb was reliable $\left[F_{1}(1,62)=4.32, p<.05 ; F_{2}(1,27)=23.33, p<\right.$ $.01]$, with first-pass reading times being shorter when the context and the target sentence contained the same verb $(M=137.3 \mathrm{msec})$ than when the verbs were different $(M=170.1 \mathrm{msec})$. This effect is probably a spillover effect from the previous region. It may be due to repetition priming, or it may indicate that readers are able to form referential links between the context and the target sentence and, therefore, develop a more coherent discourse representation when the verb is repeated than when it is not. No other effects approached significance (all $p$ s > .11).

Our main prediction was for an interaction between the context and the target factors, with more difficulty when the context and the target were incompatible than when they were compatible. Such an effect might emerge at the disambiguating noun (Region 5), but earlier we predicted that the effect would most likely be somewhat delayed. In Region 5 (the noun), there were no reliable effects or interactions on first-fixation duration or firstpass reading times (all $p$ s > .08). However, in Region 6 (the spillover region), the interaction between the context and the target sentence for first-pass reading times was almost significant by subjects and items $\left[F_{1}(1,62)=\right.$ $3.65, p=.06 ; F_{2}(1,27)=4.03, p=.06$; see Figure 1]. This suggests that readers spent a longer time reading this region of target sentences when they were congruent with the context than when they were incongruent. No other effects approached significance (all $p$ s $>.21$ ). First-pass times for Region 7 tended toward a similar interaction between the context and the target sentence $\left[F_{1}(1,62)=\right.$ $\left.3.80, p=.06 ; F_{2}(1,27)=2.87, p=.10\right]$, as well as a main effect of verb that was reliable by items only $\left[F_{1}(1,62)=\right.$ $\left.1.50, p>.05 ; F_{2}(1,27)=9.91, p<.01\right] .{ }^{1}$ No other effects approached significance (all $p \mathrm{~s}>.14$ ).

It is reasonable to expect the pattern of effects that occurred during the first pass to appear in later reading time measures. Indeed, the rereading time analyses produced a similar significant interaction between context and target sentence $\left[F_{1}(1,62)=6.95, p<.05 ; F_{2}(1,27)=\right.$ $5.92, p<.05]$. Again, the participants spent longer rereading incongruent than congruent target sentences. The analyses also revealed a main effect of verb that was reliable by items alone $\left[F_{1}(1,62)=1.22, p>.05\right.$; $\left.F_{2}(1,27)=8.38, p<.01\right]$, which suggested that the participants spent a longer time rereading target sentences when the verb was repeated than when it was not repeated. No other effects approached significance (all $p$ s $>.15)$.

The total reading times for Regions $2,3,4$, and 5 showed no reliable main effects or interactions (all $p \mathrm{~s}>$ $.05)$. In Region 6, we obtained a reliable interaction between context sentence and target sentence $\left[F_{1}(1,62)=\right.$ $\left.7.27, p<.01 ; F_{2}(1,27)=8.45, p<.01\right]$, again with incongruent texts being harder than congruent texts. There was also a main effect of verb that was significant by items alone $\left[F_{1}(1,62)<1 ; F_{2}(1,27)=7.00, p<.05\right]$. No

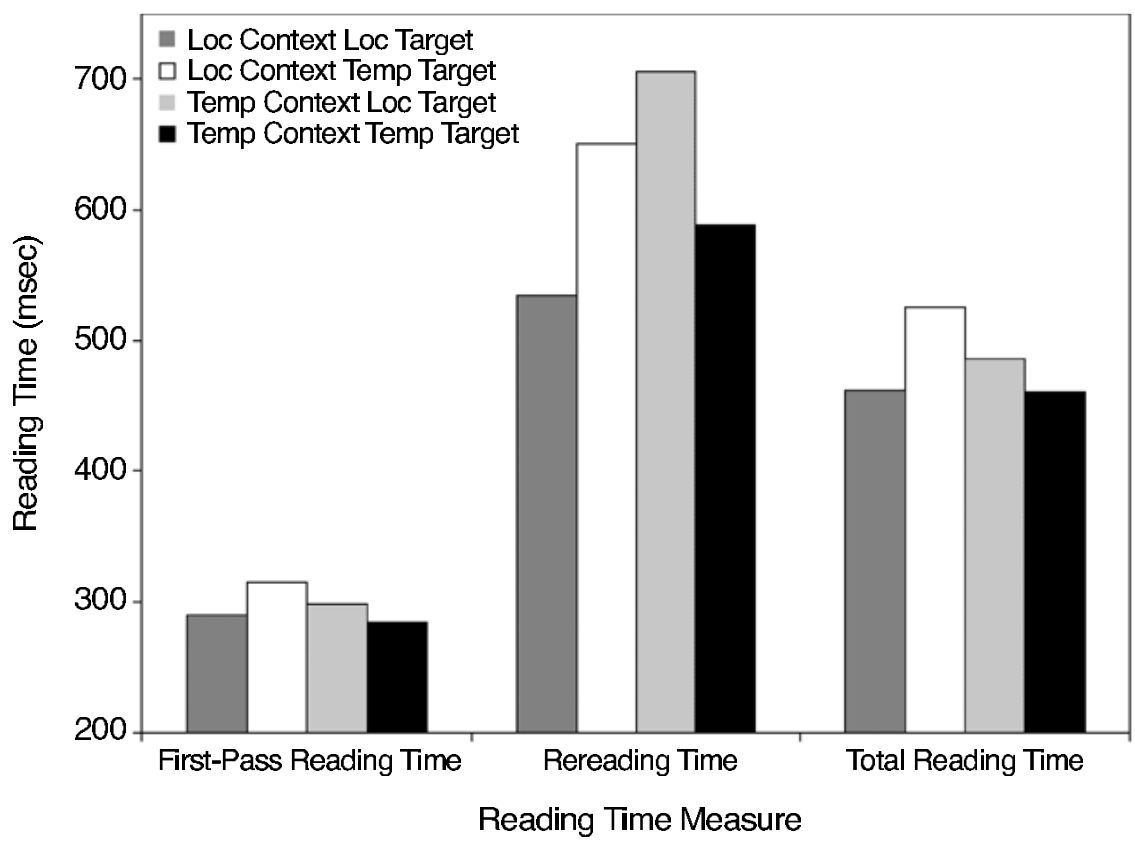

Figure 1. Mean first-pass and total reading times for Region 6 and mean rereading times for locative and temporal target sentences after locative and temporal context sentences (collapsed across the variable verb). 
other effects were significant (all $p \mathrm{~s}>.06$ ). We also obtained a similar interaction in Region $7\left[F_{1}(1,62)=6.66\right.$, $\left.p=.01 ; F_{2}(1,27)=9.00, p<.01\right]$.

\section{DISCUSSION}

Our experiment demonstrated that reading a target sentence containing an adjunct that was incongruent with context caused processing difficulty in relation to an adjunct that was congruent with context. The effect did not emerge on the disambiguating noun itself but occurred, instead, in the following two regions. It was marginal for first-pass time on the spillover and final regions of the sentence but was reliable for total time in both regions and for the rereading time measure. Hence, the context did influence the thematic expectations of the reader when they processed the target sentences.

Our results are compatible with the thematic processing account developed by Liversedge et al. (1998). On this account, $w h$-words in a preceding context can cause the reader to lodge semantically vacuous thematic roles in their discourse representation. Hence, readers are able to assign the empty thematic role in the discourse representation to a constituent that they encounter. On this account, after a locative context, readers initially assigned a locative thematic role to the ambiguous prepositional phrase, and after a temporal context, readers initially assigned a temporal thematic role to the ambiguous prepositional phrase. When the phrase was incompatible with this thematic role, processing difficulty ensued. The time delay for adjuncts, as compared with arguments, would be compatible with the suggestion that adjunct processing has a slower time course than does argument processing (Boland \& Boehm-Jernigan, 1998; Ferretti et al., 2001; Schütze \& Gibson, 1999).

On a slightly different account, readers initially assigned the locative role to a locative prepositional phrase and the temporal role to a temporal prepositional phrase, irrespective of context. However, processing difficulty occurred if the context and the target sentence were incongruous. That is to say, disruption reflected an incongruity effect due to the context's inducing a thematic expectation that the target sentence ultimately did not satisfy. This account is also compatible with the finding that processing difficulty occurred downstream of the critical region (unlike Liversedge et al., 1998). Recall that the ordering of multiple adjuncts is relatively free and, therefore, locative or temporal prepositional phrases need not necessarily come first. This means that a locative target sentence (say) does not become incongruent with a temporal context sentence, because a temporal prepositional phrase could occur later in the target sentence. On this account, incongruity occurs when the reader assumes it is unlikely that the sentence contains a congruent phrase. This is likely to be somewhat downstream of the critical region in our sentences. This time delay for adjuncts, as compared with arguments, is compatible with the suggestion that adjunct processing has a slower time course than does argument processing (Boland \& Boehm-Jernigan, 1998; Ferretti et al., 2001; Schütze \& Gibson, 1999).

There was also good evidence that reading a verb a second time was easier than reading a new verb, as indicated by significant effects on Region 4 (in the) during first pass and a number of marginal effects. There does not appear to be a repeated verb penalty comparable to the repeated name penalty. Presumably, the observed facilitation was due to priming when the verb was repeated, relative to when the verbs in the context and the target sentences were different. Note that this effect contrasts in an interesting way with effects of repeating nouns, which generally produce processing difficulty (e.g., Gordon \& Hendrick, 1998). The results also suggest that repeating a verb between sentences is not stylistically awkward. This is perhaps not too surprising. In English, a pronoun can be used instead of a repeated noun phrase to refer to a focused referent. However, other than verb phrase ellipsis (e.g., do so, do it), there are no comparable alternatives for verbs. Consequently, verbs are frequently repeated between sentences, and therefore, verb repetition appears quite natural to most readers.

Finally, none of the measures revealed a three-way interaction between verb, context sentence, and target sentence. ${ }^{2}$ We therefore have no evidence to support the hypothesis that empty thematic roles are associated with specific lexical items in the discourse representation. Instead, the data are consistent with Ferretti et al. (2001) and McRae et al. (1997), who argued that readers immediately compute typical entities that might fit thematic roles associated with verbs or prepositions on the basis of their schematic knowledge representations. According to this view, it would not be essential to repeat a verb in order for context to induce a thematic bias. However, it would be unwise to draw strong conclusions in light of the fact that the numerical magnitude of the interaction between context and target sentence (i.e., the congruency effect) is greater when the verb is repeated. To summarize, the results of this eye movement experiment show that context sentences containing $w h$-words can induce thematic expectations in readers and that these expectations affect the way in which adjuncts that are ambiguous between two thematic roles are interpreted.

\section{REFERENCES}

ABney, S. P. (1989). A computational model of human parsing. Journal of Psycholinguistic Research, 18, 129-144.

Batyen, R. H., Piepenbrock, R, \& Gulikers, L. (1995). The CELEX lexical database [CD-ROM]. Philadelphia: University of Pennsylvania, Linguistic Data Consortium.

Boland, J. E., \& Boehm-Jernigan, H. (1998). Lexical constraints and prepositional phrase attachment. Journal of Memory \& Language, 39, 684-719.

Carlson, G., \& Tanenhaus, M. K. (1988). Thematic roles and language comprehension. In W. Wilkins (Ed.), Syntax and semantics 21: Thematic relations (pp. 263-288). San Diego: Academic Press.

Clifton, C., JR., Speer, S., \& Abney, S. P. (1991). Parsing arguments: 
Phrase structure and argument structure as determinants of initial parsing decisions. Journal of Memory \& Language, 30, 251-271.

DowTy, D. (1991). Thematic proto-roles and argument selection. Language, 67, 547-619.

Ferretti, T. R., McCrae, K., \& Hatherall, A. (2001). Integrating verbs, situation schemas and thematic role concepts. Journal of Memory \& Language, 44, 516-547.

Fillmore, C. (1968). The case for case. In E. Bach \& R. T. Harms (Eds.), Universals in linguistic theory (pp. 1-90). New York: Holt, Rinehart \& Winston.

Frazier, L. (1987). Sentence processing: A tutorial review. In M. Coltheart (Ed.), Attention and performance XII: The psychology of reading (pp. 559-586). Hillsdale, NJ: Erlbaum.

Gordon, P. C., \& Hendrick, R. (1998). The representation and processing of coreference in discourse. Cognitive Science, 22, 389-424.

GRUBER, J. (1965). Studies in lexical relations. Unpublished Doctoral Dissertation, Massachusetts Institute of Technology. [Distributed by the Indiana University Linguistics Club]

Liversedge, S. P., Paterson, K. B., \& Clayes, E. L. (2002). The influence of only on syntactic processing of "long" relative clause sentences. Quarterly Journal of Experimental Psychology, 55A, 225-240.

Liversedge, S. P., Pickering, M. J., Branigan, H. P., \& Van Gompel, R. P. G. (1998). Processing arguments and adjuncts in isolation and context: The case of by-phrase ambiguities in passives. Journal of Experimental Psychology: Learning, Memory, \& Cognition, 24, 461475.

MacDonald, M. C., Pearlmutter, N. J., \& Seidenberg,M. S. (1994). The lexical nature of syntactic ambiguity resolution. Psychological Review, 101, 676-703.

McRae, K., Ferretti, T. R, \& Amyote, L. (1997). Thematic roles as verb specific concepts. Language \& Cognitive Processes, 12, 137-176.

McRae, K., Spivey-Knowlton, M. J., \& Tanenhaus, M. K. (1998).
Modeling the influence of thematic fit (and other constraints) in online sentence comprehension. Journal of Memory \& Language, 38, 283-312.

Rayner, K., Carlson, M., \& Frazier, L. (1983). The interaction of syntax and semantics during sentence processing: Eye movements in the analysis of semantically biased sentences. Journal of Verbal Learning \& Verbal Behavior, 22, 358-374.

RAYNER, K., \& DUfFy, S. A. (1986). Lexical complexity and fixation times in reading: Effects of word frequency, verb complexity, and lexical ambiguity. Memory \& Cognition, 14, 191-201.

Rayner, K., \& Pollatsek, A. (1989). The psychology of reading. Englewood Cliffs, NJ: Prentice-Hall.

Schütze, C. T., \& GibSon, E. (1999). Argumenthood and English prepositional phrase attachment. Journal of Memory \& Language, 40, 409-431.

\section{NOTES}

1. Note that this reliable item effect should be disregarded, because differences in reading time between the two participant groups was confounded with the treatment effect.

2. Despite the lack of a three-way interaction, for total time in Regions 6 and 7 and rereading time for Region 7 , we conducted simple effects tests to examine whether congruity effects occurred both when the verb was repeated and when it was not. When the verb was repeated, the interaction between context and target sentence for total times was reliable in Region $6\left[F_{1}(1,31)=8.14, p<.01 ; F_{2}(1,27)=7.11, p<.05\right]$ and in Region $7\left[F_{1}(1,31)=6.14, p<.05 ; F_{2}(1,27)=8.464, p<.01\right]$ and was also reliable for rereading times in Region $7\left[F_{1}(1,31)=6.40, p<\right.$ $\left..05 ; F_{2}(1,27)=12.05, p<.01\right]$. However, when the verb was not repeated, there were no reliable interactions between context and target sentence (all $F$ s $<1$ ).

\section{APPENDIX \\ Experimental Items}

The slashes delimit analysis regions. Words before the dash occurred in the temporal conditions; words after the dash occurred in the locative conditions. The verb in the target sentence is the verb from the different-verbconditions. The verb in the same-verb conditions was the same as the second verb in the context sentence.

The maid thought about when-where to prepare the vegetables./

In fact,/ she peeled them/ in the/ morning-kitchen,/with great/ care.

The soldiers planned when-where to assault the enemy convoy./

As decided,/ they attacked it/ in the/ night-field,/ with several/tanks.

The young boy asked about when-where to construct the model aeroplanes./

As instructed,/ he built them/ in the/ afternoon-classroom,/very/ carefully.

The technicians quarrelled about when-where to mend the computer./

In fact,/ they repaired it/ in the/ lunch hour-spare room,/ without any/ difficulty.

The teachers planned when-where to make up the new timetable./

Actually,/ they devised it/ in the/ final term-large hall,/ without any/ disagreements.

The producers quarrelled over when-where to shoot the romantic scene./

Actually,/they filmed it/ in/ April-Italy,/ to everyone's/ delight.

The theatre managers wondered about when-where to advertise the new show./

In fact,/ they publicised it/ in the/ middle of winter-centre of London,/ with huge/posters.

The new owners planned when-where to decorate the caravan./

As hoped,/ they painted it/ in the/ summer-garden,/ with clear/ varnish.

The presenter arranged when-where to question the football players./

As planned,/ he interviewed them/ in/ August-France,/ for a radio/ programme.

The trainee chef wondered about when-where to slice the carrots./

In fact,/ he cut them/ in the/morning-kitchen,/ very/skilfully.

The professors considered when-where to inspect the laboratory equipment./

Actually,/they examined it/ in the/ daytime-college,/ with other/ colleagues.

The managing director thought about when-where to disclose the profits./

In fact,/ he announced them/ in/ January-Germany,/ very/ proudly. 


\section{APPENDIX (Continued)}

The party members discussed when-where to start the election campaign./

Unsurprisingly,/ they began it/ in the/ middle of winter-centre of London,/ with a new/ slogan.

The exchange student wondered about when-where to purchase the designer shoes./ In fact,/she bought them/ in/ mid June-New York,/ with a credit/ card.

The student artist thought about when-where to sketch the portraits./ Actually,/he drew them/ in the/ autumn semester-school workshop,/ with great/ enthusiasm.

The town councillors planned when-where to discuss the new legislation./ As predicted,/ they debated it/ in the/ early evening-large library,/with no/ spectators.

The policemen decided when-where to hunt for the escaped leopard./ As planned,/ they searched for it/ in the/ night-field,/ with great/ caution.

The famous surgeon arranged when-where to undertake the operations./ In fact,/ he performed them/ in / October-Nigeria,/ to universal/praise.

The head teacher arranged when-where to award the class prizes./ As planned,/ he presented them/ in the/ final term-large hall,/ to great/ applause.

The charity directors talked about when-where to issue the report./ In fact,/ they published it/ in/ August-France,/ to great/ acclaim.

The football players decided when-where to exercise for the game./ As expected,/they trained/ in/ April-Italy,/ with great/ commitment.

The criminal planned when-where to hide the stolen goods./ As intended,/ he buried them/ in the/ night-field,/ very/ carefully.

The manager decided when-where to employ new staff./

As expected,/he hired them/ in the/ tourist season-busiest branch,/ at cheap/rates.

The ballet company wondered about when-where to practise the production./ In fact,/ they rehearsed it/ in the/ holiday-theatre,/very/ thoroughly.

The headmaster pondered over when-where to discipline the disruptive pupils./ Surprisingly,/ he punished them/in the/ afternoon-classroom,/with the/ cane.

The company directors discussed when-where to set up a new branch./ In fact,/ they established it/ in/ September-Australia,/ with high/ expectations.

The fashion designers planned when-where to present the new collection./ As decided,/ they exhibited it/ in/ March-Paris,/ to good/ reviews.

The journalist thought about when-where to draft the articles./ Unsurprisingly,/ he wrote them/in the/ early evening-large library,/without much/ effort.

(Manuscript received December 28, 2001; revision accepted for publication August 5, 2002.) 